\title{
Identification of 14 Known Drugs as Inhibitors of the Main Protease of SARS-CoV-2
}

Mohammad M. Ghahremanpour, ${ }^{\dagger}$ Julian Tirado-Rives, ${ }^{\dagger}$ Maya Deshmukh,${ }^{\dagger}$ Joseph A. Ippolito, ${ }^{\dagger *}$ Chun-Hui Zhang, ${ }^{\dagger}$ Israel Cabeza de Vaca, ${ }^{\dagger}$ Maria-Elena Liosi, ${ }^{\dagger}$ Karen S. Anderson,

${ }^{\dagger}$ Department of Chemistry, Yale University, New Haven, Connecticut 06520-8107, ${ }^{\ddagger}$ Department of Pharmacology, Yale University School of Medicine, New Haven, CT 06520-8066 and "Department of Molecular Biophysics and Biochemistry, Yale University School of Medicine, New Haven, CT 06520-8066

Received August 20, 2020

S Supporting Information

Abstract: A consensus virtual screening protocol has been applied to ca. 2000 approved drugs to seek inhibitors of the main protease $\left(\mathrm{M}^{\mathrm{pro}}\right)$ of SARS-CoV-2, the virus responsible for COVID-19. 42 drugs emerged as top candidates, and after visual analyses of the predicted structures of their complexes with $\mathrm{M}^{\text {pro }}, 17$ were chosen for evaluation in a kinetic assay for $\mathrm{M}^{\text {pro }}$ inhibition. Remarkably 14 of the compounds at $100-\mu \mathrm{M}$ concentration were found to reduce the enzymatic activity and 5 provided $\mathrm{IC}_{50}$ values below $40 \mu \mathrm{M}$ : manidipine $(4.8 \mu \mathrm{M})$, boceprevir $(5.4 \mu \mathrm{M})$, lercanidipine (16.2 $\mu \mathrm{M})$, bedaquiline $(18.7 \mu \mathrm{M})$, and efonidipine $(38.5 \mu \mathrm{M})$. Structural analyses reveal a common cloverleaf pattern for the binding of the active compounds to the $\mathrm{P} 1$, P1', and P2 pockets of $\mathrm{M}^{\text {pro }}$. Further study of the most active compounds in the context of COVID-19 therapy is warranted, while all of the active compounds may provide a foundation for lead optimization to deliver valuable chemotherapeutics to combat the pandemic. 


\section{INTRODUCTION}

SARS-CoV-2, the cause of the COVID-19 pandemic, ${ }^{1}$ is a coronavirus $(\mathrm{CoV})$ from the Coronaviridae family. Its RNA genome is $\sim 82 \%$ identical to that of SARS-CoV, ${ }^{2}$ which was responsible for the Severe Acute Respiratory Syndrome (SARS) pandemic in $2003 .{ }^{3}$ SARS-CoV-2 encodes two cysteine proteases: the chymotrypsin-like cysteine or main protease, known as $3 \mathrm{CL}^{\text {pro }}$ or $\mathrm{M}^{\text {pro }}$, and the papain-like cysteine protease, $\mathrm{PL}^{\text {pro }}$. They catalyze the proteolysis of polyproteins translated from the viral genome into non-structural proteins essential for packaging the nascent virion and viral repication. ${ }^{4}$ Therefore, inhibiting the activity of these proteases would impede the replication of the virus. $\mathrm{M}^{\text {pro }}$ processes the polyprotein $1 \mathrm{ab}$ at multiple cleavage sites. It hydrolyzes the Gln-Ser peptide bond in the Leu-GlnSer-Ala-Gly recognition sequence. This cleavage site in the substrate is distinct from the peptide sequence recognized by other human cysteine proteases known to date. ${ }^{5}$ Thus, $\mathrm{M}^{\text {pro }}$ is viewed as a promising target for anti SARS-CoV-2 drug design; it has been the focus of several studies since the pandemic has emerged. ${ }^{2,4-7}$

An X-ray crystal structure of $\mathrm{M}^{\text {pro }}$ reveals that it forms a homodimer with a 2fold crystallographic symmetry axis. ${ }^{2,5}$ Each protomer, with a length of 306 residues, is made of three domains (I-III). Domains II and I fold into a six-stranded $\beta$-barrel that harbors the active site. ${ }^{2,4,5}$ Domain III forms a cluster of five antiparallel $\alpha$ helices that regulates the dimerization of the protease. A flexible loop connects domain II to domain III. The $\mathrm{M}^{\text {pro }}$ active site contains a Cys-His catalytic dyad and canonical binding pockets that are denoted $\mathrm{P} 1, \mathrm{P} 1{ }^{\prime}, \mathrm{P} 2, \mathrm{P} 3$, and $\mathrm{P} 4 .^{2}$ The amino acid sequence of the active site is highly conserved among coronaviruses. ${ }^{8}$ The catalytic dyad residues are $\mathrm{His}^{41}$ and $\mathrm{Cys}^{145}$ and the residues playing key roles in the binding 


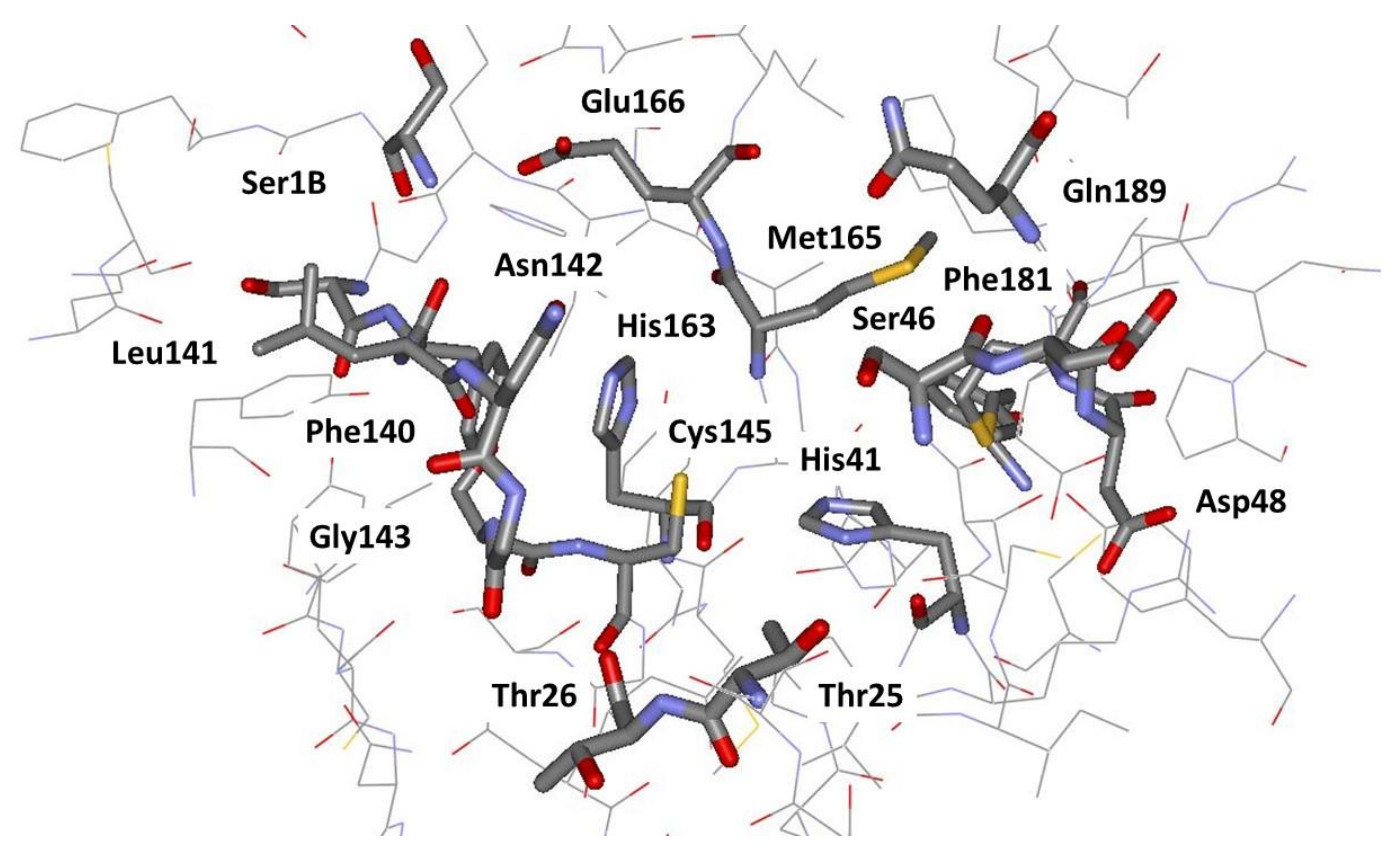

Figure 1. Rendering of the residues near the catalytic site of $\mathrm{M}^{\text {Pro }}$ from a crystal structure at 1.31- $\AA$ resolution (PDB ID: 5R82). The catalytic residues are His41 and Cys145.

of the substrate are $\mathrm{Phe}^{140}$, His ${ }^{163}, \mathrm{Met}^{165}, \mathrm{Glu}^{166}$, and $\mathrm{Gln}^{189}$ (Figure 1). These residues have been found to interact with the ligands co-crystallized with $\mathrm{M}^{\text {pro }}$ in different studies. ${ }^{2,4,5}$ Crystallographic data also suggested that $\operatorname{Ser}^{1}$ of one protomer interacts with $\mathrm{Phe}^{140}$ and Glu${ }^{166}$ of the other as the result of dimerization. ${ }^{2,4}$ These interactions stabilize the P1 binding pocket, thereby, dimerization of the main protease is likely for its catalytic activity. ${ }^{2,4}$

Drug repurposing is an important strategy for immediate response to the COVID-19 pandemic. $^{9}$ In this approach, the main goal of computational and experimental studies has been to find existing drugs that might be effective against SARS-CoV-2. For instance, a molecular docking study suggested remdesivir as a potential therapeutic that could be used against SARS-CoV-2, ${ }^{10}$ which was supported experimentally by an $\mathrm{EC}_{50}$ value of $23 \mu \mathrm{M}$ in an infected-cell assay. ${ }^{11}$ However, a clinical trial showed no statistically significant clinical benefits of remdesivir on 
adult patients hospitalized for severe COVID-19. ${ }^{12}$ Nonetheless, patients who were administered remdesivir in the same trial showed a faster time to clinical improvement in comparison to the placebo-control group. ${ }^{12}$ In another clinical trial, only patients on mechanical ventilation benefitted from remdesivir. ${ }^{13}$ An $\mathrm{EC}_{50}$ value of $27 \mu \mathrm{M}$ was also reported for lopinavir ${ }^{11}$, suggesting it may have beneficial activity against SARS-CoV-2. However, neither lopinavir nor the lopinavir/ritonavir combination has thus far shown any significant benefits against COVID-19 in clinical trials. Chloroquine, hydroxychloroquine, and favipiravir have also been explored for repurposing against COVID-19; however, clinical studies with them have been controversial. ${ }^{14-17}$ These studies reflect the urgent need for systematic drug discovery efforts for therapies effective against SARS-CoV-2.

Thus, we decided to pursue discovery of small-molecule inhibitors of $\mathrm{M}^{\text {pro }}$. The aim of this initial work was two-fold: to identify known drugs that may show some activity, but also to identify structurally promising, synthetically-accessible substructures suitable for subsequent lead optimization. Our expectation was that existing drugs may show activity but not at the low-nanomolar levels that are typical of effective therapies. This report provides results for the first goal. The work began by designing and executing a consensus molecular docking protocol to virtual screen 2000 approved drugs. The predicted structures (poses) of the complexes for the topscoring 42 drugs received extensive scrutiny including consideration of intermolecular contacts, conformation, stability in molecular dynamics (MD) simulations, and potential for synthetic modification to arrive at 17 drugs, which were purchased and assayed for inhibition of $\mathrm{M}^{\text {pro }}$. The outcome was strikingly successful with 14 of the 17 compounds showing some reduction of $\mathrm{M}^{\text {pro }}$ activity at $100 \mu \mathrm{M}$ concentration, and with 5 compounds yielding $\mathrm{IC}_{50}$ values below $40 \mu \mathrm{M}$. 
The most potent inhibitors of $\mathrm{M}^{\text {pro }}$ identified here, manidipine and boceprevir, have $\mathrm{IC}_{50}$ values of 4.8 and $5.4 \mu \mathrm{M}$, respectively.

\section{COMPUTATIONAL APPROACH}

Selection of the Crystal Structure of $\mathbf{M}^{\text {pro. }}$. Our analyses of more than 50 crystal structures of SARS-CoV-2 main protease in apo and holo forms showed small structural variations in the active site region. The overall root mean square deviation (RMSD) of all structures was $\sim 0.8 \AA$ for $\mathrm{C}_{\alpha}$ atoms. The presence of a ligand in the crystal structure likely places the side chains of the active site residues in positions that are more suitable for performing molecular docking compared to the apo form of the enzyme. Thus, we chose to use a high-resolution (1.31 $\AA$ ) structure of $\mathrm{M}^{\text {pro }}$ cocrystalized with a non-covalent small fragment hit (PDB ID 5R82) ${ }^{18}$ for docking the approved drugs after removal of the fragment (Figure 1). The program Reduce ${ }^{19}$ was run on the structure for allowing side-chain flips, optimizing hydrogen bonds, and adding/removing hydrogen atoms. The $\mathrm{pKa}$ values of the ionizable residues of $\mathrm{M}^{\text {pro }}$ were predicted using the PROPKA $3^{20}$ and the H++ severs. ${ }^{21,22}$ Accordingly, lysines and arginines were positively charged, aspartic and glutamic acids were negatively charged, and all histidines were neutral. All histidines were built with the proton on $\mathrm{N} \varepsilon$ except for His80, which was protonated at $\mathrm{N} \delta$. The resulting $\mathrm{M}^{\text {pro }}$ structure has a net charge of $-4 e$. Extensive visual inspection was carried out using UCSF Chimera. ${ }^{23}$

Consensus Molecular Docking. Most docking programs apply methods to generate an initial set of conformations, and tautomeric and protonation states for each ligand. This is followed by application of search algorithms and scoring functions to generate and score the poses of the ligand in the binding site of a protein. Scoring functions have been trained to reproduce a finite set of experimental ligand- 
binding affinities that are generally a mix of activity data converted to a free-energy scale. Therefore, the accuracy of the scores is dependent on multiple factors including the compounds that were part of the training set. To mitigate the biases, we performed four independent runs of protein-ligand docking with a library of ca. 2000 approved, oral drugs using Glide, AutoDock Vina, and two protocols with AutoDock 4.2. The results were compiled and further consideration focused on those compounds that ranked among the top $10 \%$ percent in at least 3 out of the 4 runs.

Glide. Schrödinger's Protein Prep wizard utility was used for preparing the protein. A 20 - $\AA$ grid was then generated and centered on the co-crystallized ligand, which was subsequently removed. The drug library members were neutralized and/or ionized via Schrödinger's LigPrep. ${ }^{24}$ The Epik program ${ }^{25}$ was used for estimating the $\mathrm{pKa}$ values of each compound. Plausible tautomers and stereoisomers within the $\mathrm{pH}$ range of $7 \pm 1$ were generated for each compound using the OPLS3 force field. ${ }^{26}$ These conditions resulted in a total of 16000 structures, which were then docked into $\mathrm{M}^{\text {pro }}$ using Schrödinger's standard-precision (SP) Glide. ${ }^{27,28}$

AutoDock. The AutoDockTools (ADT) software $^{29}$ was used for creating PDBQT files from SDF and PDB files of compounds and the protein, respectively. Non-polar hydrogen atoms were removed and Gasteiger-Marsili charges were assigned for both the protein and the ligands using ADT. The AutoGrid 4.2 program $^{29}$ was used for generating affinity grids with a spacing of $0.375 \AA$ and with a box size of $74 \times 80 \times 62 \AA$. The affinity grids were centered at two different points of the active site for performing two sets of runs. In the first run, the grid box was centered at $\mathrm{C}_{\beta}$ of Cys145 of monomer $\mathrm{A}$. In the second run, the grid center was displaced toward the geometric center of the active site. The AutoDock 4.2 program $^{29}$ was applied for docking the ligands into $\mathrm{M}^{\text {pro }}$. The Lamarckian genetic algorithm (LGA) 
was used for ligand conformational searching. LGA was iterated 15 and 50 times in the first and the second run, respectively, for each compound. The maximum RMS tolerance for conformational cluster analysis was 2.0 and $0.5 \AA$ in the first and second runs, respectively. The number of generations was set to 27000 with 300 individuals in each population in both runs. The maximum number of energy evaluations was 30 $\times 10^{6}$ for all compounds and $40 \times 10^{6}$ for re-docking of the selected consensus compounds. Other parameters were set to their default values.

AutoDock Vina. The PDBQT files generated by ADT for the protein and library compounds also used for running AutoDock Vina. ${ }^{30}$ Non-polar hydrogen atoms were removed. An affinity grid box with a size of $18 \times 21 \times 18 \AA$ was generated and centered on the active site. The default docking parameters were used, except for the number of modes that was set to 9 .

Molecular Dynamics Simulations. The GROMACS software, version 2018a compiled in double precision, was used for performing all molecular dynamics (MD) simulations. ${ }^{31}$ The protonated $\mathrm{M}^{\text {pro }}$ dimer, with a net charge of $-8 e$, was represented by the OPLS-AA/M force field. ${ }^{32}$ TIP4P water was used as the solvent. ${ }^{33}$ Sodium counterions were added to neutralize the net charge of each system. The selected ligand candidates were represented by the OPLS/CM1A force field, ${ }^{34}$ as assigned by the BOSS software ${ }^{35}$ (version 4.9) and the LigParGen Python code. ${ }^{36}$ The parameters were converted to GROMACS format using LigParGen. ${ }^{36}$ For neutral ligands, the CM1A partial atomic charges were scaled by a factor of $1.14 .{ }^{34}$

Each $\mathrm{M}^{\text {pro }}$-ligand complex was put at the center of a triclinic simulation box with 10 - $\AA$ padding. An energy minimization was then performed until the steepest descent algorithm converged to a maximum force smaller than $2.4 \mathrm{kcal} \mathrm{mol}^{-1} \AA^{-1}$. A cutoff radius of $12 \AA$ was used to explicitly calculate non-bonded interactions. Long- 
range electrostatic interactions were treated using the Particle Mesh Ewald (PME) algorithm. ${ }^{37}$ The PME was used with an interpolation order of 4, a Fourier spacing of $1.2 \AA$, and a relative tolerance of $10^{-6}$. The van der Waals forces were smoothly switched to zero between 10 and $12 \AA$. Analytical corrections to the long-range effect of dispersion interactions were applied to both energy and pressure. All covalent bonds to hydrogen atoms were constrained at their equilibrium lengths using the LINCS algorithm ${ }^{38}$ with the order of 12 in the expansion of the constraint-coupling matrix. Each system was subsequently simulated for $1 \mathrm{~ns}$ in the canonical ensemble $(N V T)$ in order for the solvent to relax and the temperature of the system to equilibrate. Initial velocities were sampled from a Maxwell-Boltzmann distribution at $310 \mathrm{~K}$. The V-rescale thermostat with a stochastic term ${ }^{39}$ was used for keeping the temperature at $310 \mathrm{~K}$. The stochastic term ensured that the sampled ensemble was canonical. ${ }^{39}$ The coupling constant of the thermostat was set to 2.0 ps. The system was then equilibrated for $1.5 \mathrm{~ns}$ in the isothermal-isobaric ensemble (NPT) for obtaining a density consistent with the reference pressure. The pressure was kept at 1 bar by the Berendsen barostat ${ }^{40}$ with a coupling constant of 4.0 ps and a compressibility factor of $4.5 \times 10^{-5}$ bar. A harmonic position restraint with a force constant of $2.4 \mathrm{kcal} \mathrm{mol}^{-1} \AA^{-2}$ was applied to the protein backbone and to all solute heavy atoms during the equilibration steps. A $70 \mathrm{~ns}$ unrestrained run was then performed in the NPT ensemble with the Parrinello-Rahman barostat ${ }^{41}$ using a coupling time of $4.0 \mathrm{ps}$. 


\section{EXPERIMENTAL DETAILS}

Expression and Purification of SARS-CoV-2 Mpro. A PGEX-6p-1 vector containing the gene for SARS-CoV-2 $\mathrm{M}^{\text {pro }}$ harboring a His6 tag followed by a modified PreScission cleavage site was used to produce recombinant protein. ${ }^{5}$ Recombinant $\mathrm{M}^{\text {pro }}$ with authentic $\mathrm{N}$ - and $\mathrm{C}$-termini was expressed and purified as previously described. ${ }^{5}$

Kinetic Assays of SARS-CoV-2 Mpro Activity and Analysis. All assayed compounds were obtained from commercial sources except cinnoxicam, which had to be synthesized, and had purity $>95 \%$ based on HPLC analysis. Kinetics of SARSCoV-2 $\mathrm{M}^{\text {pro }}$ were measured as previously described. ${ }^{5,7}$ Briefly, $100 \mathrm{nM} \mathrm{M}^{\text {pro }}$ in reaction buffer (20mM Tris, $100 \mathrm{mM} \mathrm{NaCl}, 1 \mathrm{mM}$ DTT, $\mathrm{pH}$ 7.3) was incubated with or without compound in DMSO at varying concentrations to a final DMSO concentration of $6 \%$ for 15 minutes with shaking at room temperature. The reaction was initiated by addition of substrate (Dabcyl-KTSAVLQ $\downarrow$ SGFRKM-E(Edans-NH2); GL Biochem) in reaction buffer, which is cleaved by $\mathrm{M}^{\text {pro }}$, generating a product containing a free Edans group. Fluorescence was monitored at an excitation wavelength of $360 \mathrm{~nm}$ and emission wavelength of $460 \mathrm{~nm}$. All measurements were performed in triplicate and averaged. $\mathrm{IC}_{50}$ plots and values were generated using Prism 8.0 (GraphPad).

\section{RESULTS AND DISCUSSION}

Virtual Screening. The docking scores obtained for all compounds range from -10.85 to -0.59 for Glide, from -12.33 to -2.30 for AutoDock run 1 , from -10.74 to -0.40 for AutoDock run 2, and -8.50 to -2.10 for AutoDock Vina. As expected, the range of scores is wide and it is different from one docking program to another. The 
complete list of compounds and docking scores is provided in the SI. Compounds were ranked based on their docking scores and the top 200 hits from the four docking runs were compared. As the result, 42 compounds with a consensus count of 4 or 3 were selected. This means that these compounds were among the top-200 ranked compounds in all 4 or at least 3 out of the 4 docking runs. The indications and mechanisms of action for the 42 drugs are shown in Table 1, and the structures of some of the ones that turned out to be most interesting are shown in Figure 2. The primary indications include bacterial and viral infections, hypertension, psychosis, inflammation, and cancer. Their mechanisms of action are also broad ranging from kinase and protease inhibitors to dopamine receptors agonists/antagonists, and calcium channel blockers. It is not surprising that peptidic protease inhibitors are well-represented in view of the peptide substrate and prior discovery of peptidic inhibitors for $\mathrm{M}^{\text {pro }}$ and its SARS-CoV relative. ${ }^{7,42,43}$

In almost all cases the predicted poses for the 42 compounds from the different docking programs agreed well. The poses from Glide were then subjected to extensive visual scrutiny to check for unsatisfied hydrogen-bonding sites, electrostatic mismatches, and unlikely conformation of the ligand. About half of the compounds were ruled out for further study due to the occurrence of such liabilities and the presence of multiple ester groups (e.g., methoserpidine and nicomol) or overall size and complexity (e.g., bromocriptine and benzquercin). A repeated motif was apparent with high-scoring ligands having a cloverleaf pattern with occupancy of the P1, P1', and P2 pockets, as illustrated in Figure 3 for the complex of azelastine. Other common elements are an edge-to-face aryl-aryl interaction with His41 and placement of a positively-charged group in the P1 pocket in proximity to Glu166, e.g., the methylazepanium group of azelastine, the protonated trialkylamino group of 
Table 1. The Consensus Count (CC), Indication and Mechanism of Action of the Top 42 Drugs Selected from Virtual Screening. Assayed Compounds are in Bold.

\begin{tabular}{|c|c|c|c|}
\hline Compound & $\mathbf{C C}$ & Indication & Mechanism of Action \\
\hline avatrombopag maleate & 3 & Thrombocytopenia & Thrombopoietin receptor agonist \\
\hline azelastine & 4 & Allergic rhinitis & Histamine H1-receptors antagonist \\
\hline azilsartan Medoxomil & 4 & Hypertension & Angiotensin II receptor antagonist \\
\hline bedaquiline & 3 & Tuberculosis & ATP synthase inhibitor \\
\hline benzquercin & 4 & Inflammation & Flavonoid drug \\
\hline boceprevir & 3 & Hepatitis C & Protease inhibitor \\
\hline bromocriptine & 4 & Hyperprolactinemic disorders & Dopamine $\mathrm{D}_{2}$ receptor agonist \\
\hline cabergoline & 4 & Hyperprolactinemic disorders & Dopamine $\mathrm{D}_{2}$ receptor agonist \\
\hline carindacillin & 4 & Bacterial infection & Penicillin-binding protein \\
\hline cinnoxicam & 4 & Inflammation & Prostaglandin synthesis inhibitor \\
\hline clofazimine & 4 & Lepromatous leprosy & Destabilizing bacterial membrane \\
\hline dexetimide & 3 & Neuroleptic parkinsonism & Muscarinic antagonist \\
\hline dihydroergocristine & 4 & Peripheral vascular disease & Serotonin receptors antagonist \\
\hline dihydroergocryptine & 4 & Parkinson's disease & Dopamine receptor agonist \\
\hline efonidipine & 4 & Hypertension & Calcium channel blocker \\
\hline elbasvir & 3 & Hepatitis C & Protein 5A inhibitor \\
\hline idarubicin & 4 & Acute myeloid leukemia & Topoisomerase II inhibitor \\
\hline indinavir & 3 & HIV infection & Protease inhibitor \\
\hline ketoconazole & 3 & Fungal infection & $14-\alpha$-sterol demethylase inhibitor \\
\hline lapatinib & 4 & Breast and lung cancer & Kinase inhibitor \\
\hline lercanidipine & 4 & Hypertension & Calcium channel blocker \\
\hline lomitapide & 3 & Hypercholesterolemia & Triglyceride transfer inhibitor \\
\hline lurasidone & 4 & Schizophrenia & Dopamine $\mathrm{D}_{2}$ receptor antagonist \\
\hline macimorelin & 3 & Adult growth hormone deficiency & Ghrelin receptor agonist \\
\hline manidipine & 3 & Hypertension & Calcium channel blocker \\
\hline metergoline & 4 & Psychosis & Dopamine agonist \\
\hline methoserpidine & 3 & Hypertension & Monoamine transport inhibitor \\
\hline naldemedine & 3 & Opioid induced constipation & Opioid receptor antagonist \\
\hline nelfinavir & 3 & HIV infection & Protease inhibitor \\
\hline nicomol & 3 & Hyperlipidemia & - \\
\hline nicomorphine & 4 & Analgesic & Opioid agonist \\
\hline nilotinib & 4 & Chronic myeloid leukemia & Kinase inhibitor \\
\hline perampanel & 4 & Partial-onset seizures & Glutamate receptor antagonist \\
\hline periciazine & 3 & Psychosis & Dopamine $\mathrm{D}_{1}$ receptor antagonist \\
\hline pipamazine & 3 & Psychosis & Dopamine receptor antagonist \\
\hline saquinavir & 4 & HIV infection & Protease inhibitor \\
\hline simvastatin & 3 & Hyperlipidemia & HMG-CoA reductase inhibitor \\
\hline talampicillin & 3 & Antibacterial & Cell-wall synthesis inhibitor \\
\hline telaprevir & 3 & Hepatitis C & Protease inhibitor \\
\hline tipranavir & 3 & HIV infection & Protease inhibitor \\
\hline tropesin & 3 & Inflammation & Prostaglandin synthesis inhibitor \\
\hline zafirlukast & 4 & Asthma & Leukotriene receptor antagonist \\
\hline
\end{tabular}


<smiles>COC(=O)C1=C(C)NC(C)C(C(=O)OCCN2CCN(C(c3ccccc3)c3ccccc3)CC2)C1c1cccc([N+](=O)[O-])c1</smiles>

Manidipine

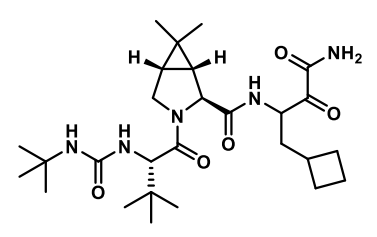

Boceprevir<smiles>COC(=O)C1=C(C)NC(C)=C(C(=O)OC(C)(C)CN(C)CCc2ccccc2)C1c1cccc([N+](=O)[O-])c1</smiles>

Lercanidipine<smiles>CC1=C(C(=O)OCC(C)(C)C)C(C(=O)OCCN(Cc2ccccc2)c2ccccc2)C(C(=O)OCC(C)(C)C)=C(C)N1</smiles>

Efonidipine<smiles>CNCCC(c1ccccc1)(c1ccccc1)c1cccc2ccccc12</smiles>

Bedaquiline<smiles>N#Cc1ccccc1C(=O)c1cc(-c2ccccc2)cn1-c1ccccc1</smiles>

Perampanel<smiles></smiles>

Periciazine<smiles>CN1CCC([N+]2(Cc3ccc(Cl)cc3)C(=O)c3ccccc3C2=O)CC1</smiles>

Azelastine

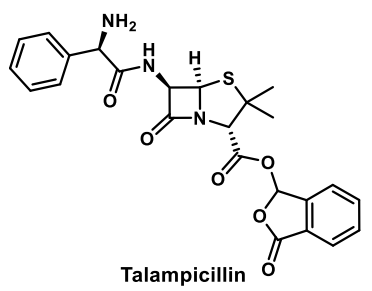

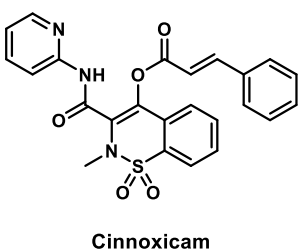<smiles>C[C@H](NC(=O)C(CCCN1CCN(Cc2ccc[nH]2)CC1)Cc1ccccc1)C(=O)NC(C)(C)C(C)(C)C</smiles>

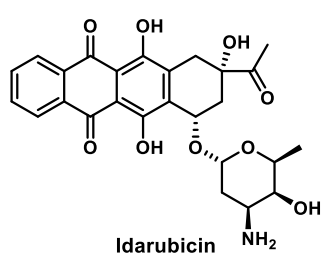

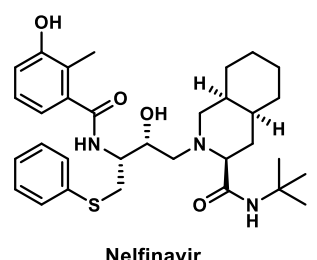

Nelfinavir<smiles>Cc1cccc(COc2ccc(N(C)c3ncnc4ccc(-c5ccc(CCNCCC(C)(O)O)o5)cc34)cc2Cl)c1</smiles>

Lapatinib

Figure 2. Selected high-scoring compounds from the consensus docking.
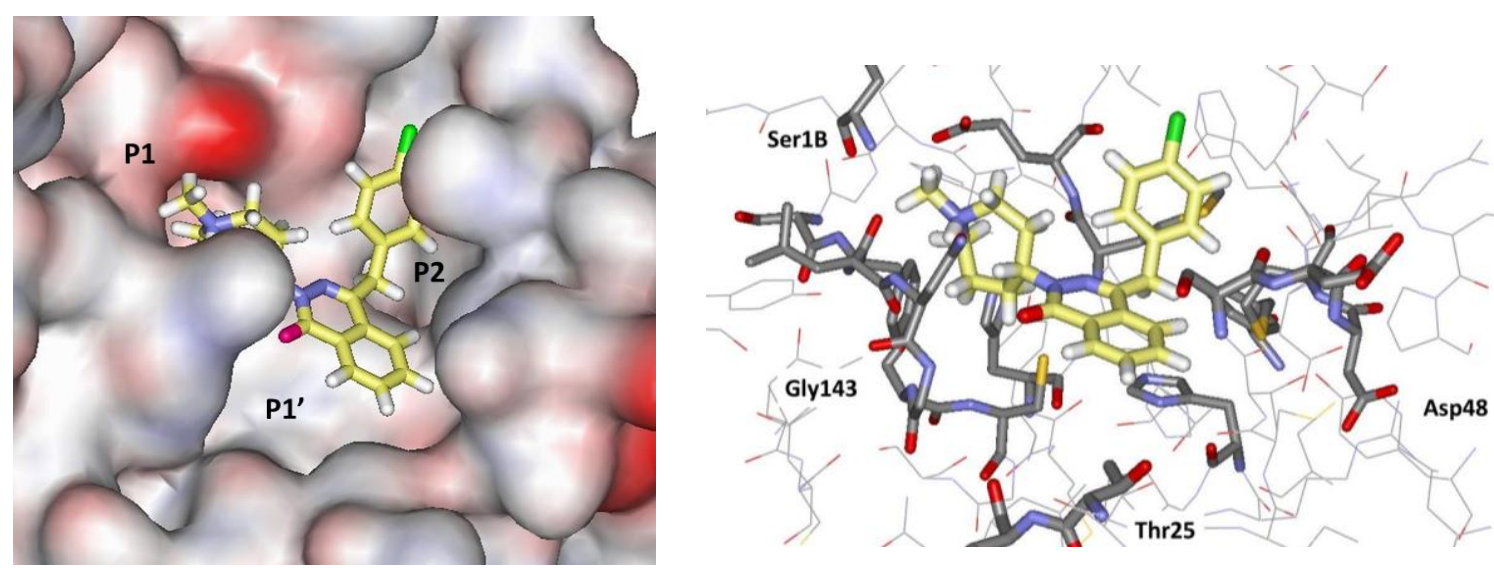

Figure 3. Glide docking pose for azelastine in space-filling (left) and stick (right) renderings. All illustrations are oriented with the P1 pocket to the left and P2 to the right, and all carbon atoms of ligands are in yellow. 
bedaquiline, and protonated piperazine of periciazine. However, Glu166 forms a saltbridge with the terminal ammonium group Ser1B (Figure 1). The electrostatic balance seems unclear in this region, so our final selections included a mix of neutral and positively-charged groups for the P1 site.

The analysis of the high-scoring 42 compounds also considered structural variety and potential synthesis of analogs. In the end, we settled on 17 compounds, which are highlighted in Table 1, for purchase and assaying. Sixteen were commercially available, mostly from Sigma-Aldrich. The seventeenth, cinnoxicam, was not available, but it was readily prepared in a one-step synthesis from the commercially-available ester components. It may be noted that three calcium channel blockers, efonidipine, lercanidipine, and manidipine were purchased (Figure 2). This was not done owing to the characteristic dihydropyridine substructure, since this end of the molecule protrudes out of the P1' site in the docked poses. It was for the variety in the left-sides of the molecules in Figure 2, which form the cloverleaf that binds in the P1, P1', and P2 pockets, as illustrated in Figure 4 for manidipine. The steric fit in this region appears good, though the only potential hydrogen bond is between the nitro group and the catalytic Cys145.
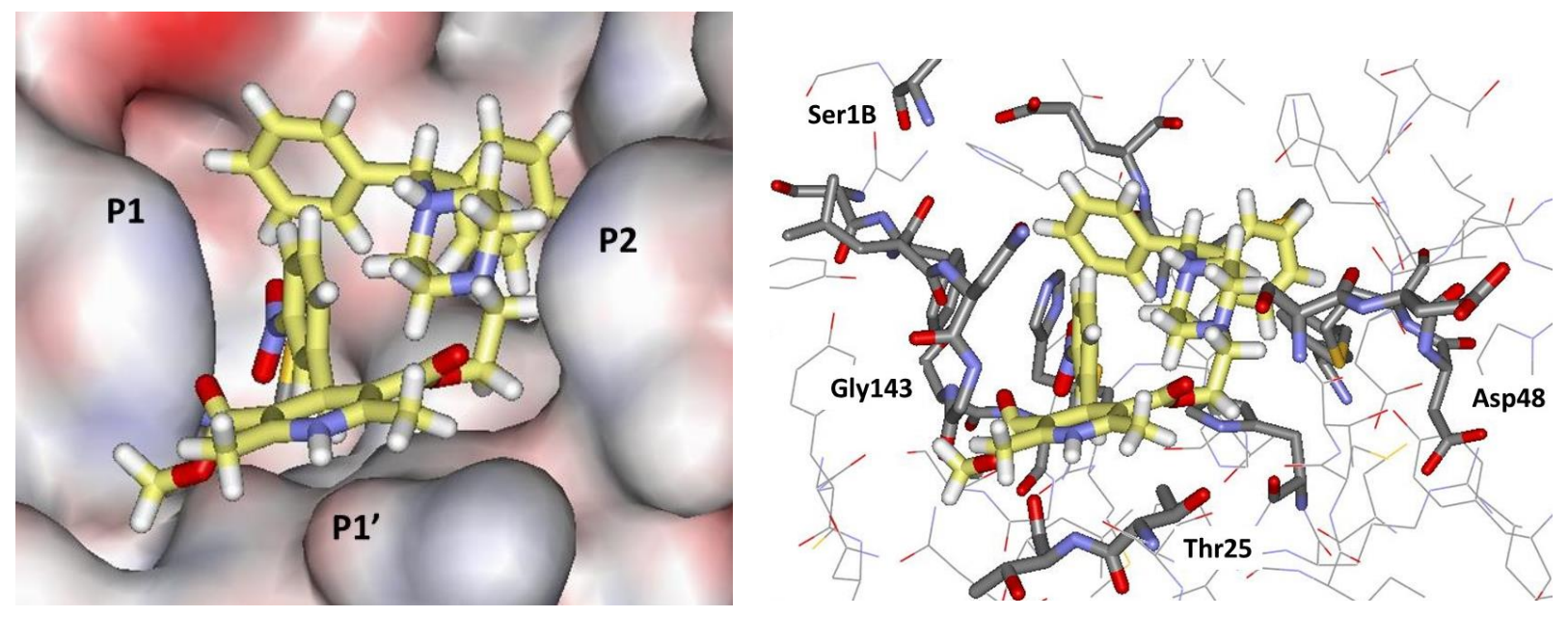

Figure 4. Glide docking pose for manidipine in space-filling (left) and stick (right) renderings. 
Protease Assay Results. The 17 known drugs were screened using the FRETbased assay monitoring the fluorescence generated from the cleavage of a peptide substrate harboring an Edans-Dabcyl pair by recombinant SARS-CoV-2 $\mathrm{M}^{\text {pro }}$. Remarkably, fourteen of the drugs at $100 \mu \mathrm{M}$ decreased $\mathrm{M}^{\text {pro }}$ activity (100 $\left.\mathrm{nM}\right)$, as shown in Figure 5 and Table 2. Five drugs decreased $\mathrm{M}^{\text {pro }}$ activity to below $40 \%$. The top five hits from the kinetic assay were manidipine, boceprevir, efonidipine, lercanidipine, and bedaquiline. Dose-response curves were obtained to determine $\mathrm{IC}_{50}$ values, when possible, as shown in Figure 6 for the five most potent inhibitors, with the raw data as a function of time and concentration given in Figure S1.

The calcium channel-blockers manidipine, lercanidipine, and efonidipine inhibit $\mathrm{M}^{\text {pro }}$ activity with $\mathrm{IC}_{50}$ values of $4.8 \mu \mathrm{M}, 16.2 \mu \mathrm{M}$, and $38.5 \mu \mathrm{M}$, respectively. As suggested from Figure 4, the variation likely arises primarily from differences in binding of the left sides of the molecules (Figure 2) in the P1, P1', and P2 pockets. It has previously been proposed that such compounds might be useful for treatment of SARS-CoV-2 infection for their role as calcium channel blockers, not as $\mathrm{M}^{\text {pro }}$ inhibitors. ${ }^{44}$ Boceprevir, a hepatitis $\mathrm{C}$ virus protease inhibitor, inhibits $\mathrm{M}^{\text {pro }}$ with an $\mathrm{IC}_{50}$ of $5.4 \mu \mathrm{M}$; its $\mathrm{IC}_{50}$ has been previously reported as $4.13 \mu \mathrm{M} .^{7}$ Bedaquiline, approved for the treatment of multi-drug-resistant tuberculosis, inhibits $\mathrm{M}^{\text {pro }}$ with an $\mathrm{IC}_{50}$ of $18.7 \mu \mathrm{M}$. The $\mathrm{IC}_{50}$ of nelfinavir, an HIV protease inhibitor, was estimated to be between 250 and $600 \mu \mathrm{M}$. Vatansever et al. have previously reported an $\mathrm{IC}_{50}$ for nelfinavir of $234 \mu \mathrm{M} .{ }^{45}$ Perampanel appears to be the sixth most active compound at $100 \mu \mathrm{M}$, though its $\mathrm{IC}_{50}$ could not be calculated reliably, as its intrinsic fluorescence interfered with the fluorescence measurements.

The computed structures for the complexes of boceprevir and bedaquiline are illustrated in Figure 7. For boceprevir, the dimethylcyclopropyl subunit is predicted to 


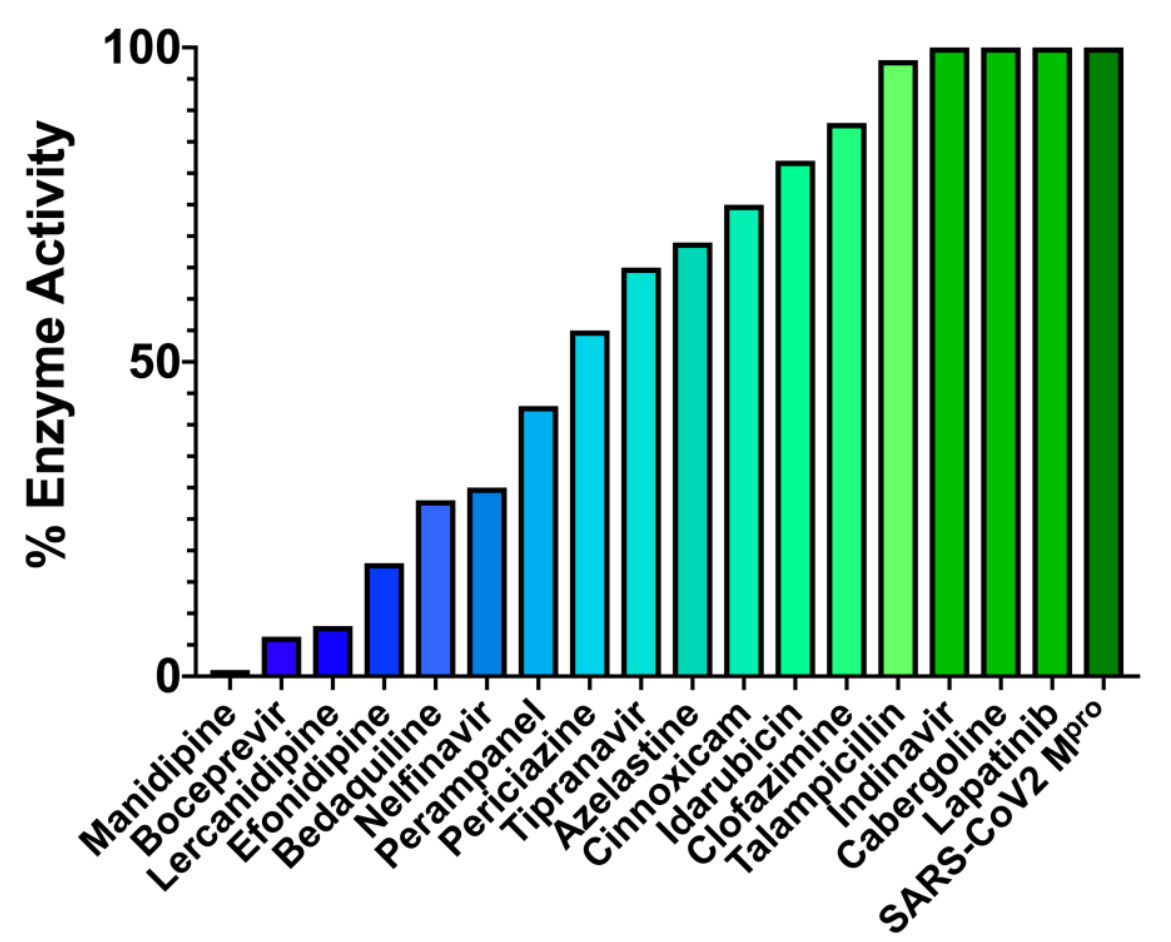

Figure 5. Ranking of the 17 compounds by percent residual enzyme activity monitored by cleavage product fluorescence following a one-hour incubation of 100 $\mathrm{nM} \mathrm{M}^{\text {pro }}$ with $100 \mu \mathrm{M}$ compound. Compounds are ranked from most (blue) to least (green) active.

Table 2. Measured Activities of the 17 Compounds Tested for Inhibition of $\mathrm{M}^{\text {pro }}$

\begin{tabular}{lcc} 
Compound & $\begin{array}{c}\text { \% Activity } \\
\text { at } \mathbf{1 0 0} \boldsymbol{\mu M}\end{array}$ & $\mathbf{I C}_{\mathbf{5 0}}(\boldsymbol{\mu M})$ \\
manidipine & 1 & $4.81 \pm 1.87$ \\
boceprevir & 6 & $5.40 \pm 1.53$ \\
lercanidipine & 8 & $16.2 \pm 2.94$ \\
efonidipine & 18 & $38.5 \pm 0.41$ \\
bedaquiline & 28 & $18.7 \pm 4.20$ \\
perampanel & 43 & $100-250^{\mathrm{a}, \mathrm{b}}$ \\
periciazine & 55 & $250^{\mathrm{a}}$ \\
nelfinavir & 64 & $250-600^{\mathrm{a}}$ \\
tipranavir & 65 & $>600^{\mathrm{a}}$ \\
azelastine & 69 & $20-100^{\mathrm{a}}$ \\
cinnoxicam & 75 & $>600^{\mathrm{a}}$ \\
idarubicin & 82 & $250-600^{\mathrm{a}}$ \\
clofamizine & 88 & $>600^{\mathrm{a}}$ \\
talampicillin & 90 & $250-600^{\mathrm{a}}$ \\
indinavir & 100 & $\mathrm{NA}$ \\
cabergoline & 100 & $\mathrm{NA}$ \\
lapatinib & 100 & $\mathrm{NA}$ \\
\hline
\end{tabular}

${ }^{\mathrm{a}}$ Estimate due to incomplete inhibition at $600 \mu \mathrm{M} .{ }^{\mathrm{b}}$ Fluorescence of compound interfered with assay. 

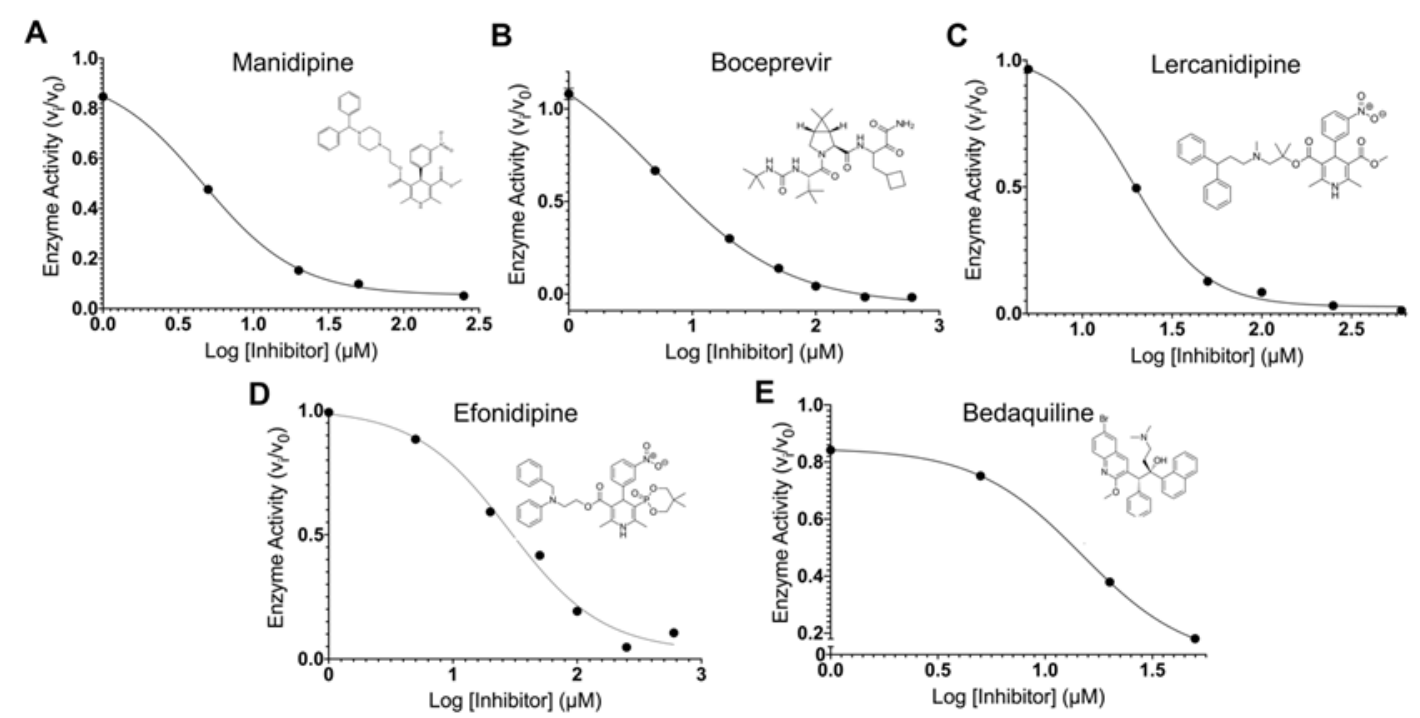

Figure 6. $\mathrm{IC}_{50}$ plots and values for the top five compounds active against SARS-CoV$2 \mathrm{M}^{\text {pro }}$ from in vitro FRET-based assay. $\mathrm{IC}_{50}$ plots were generated from averaged kinetic data in triplicates for (A) manidipine, (B) boceprevir, (C) lercanidipine, (D) efonidipine, and (E) bedaquiline.
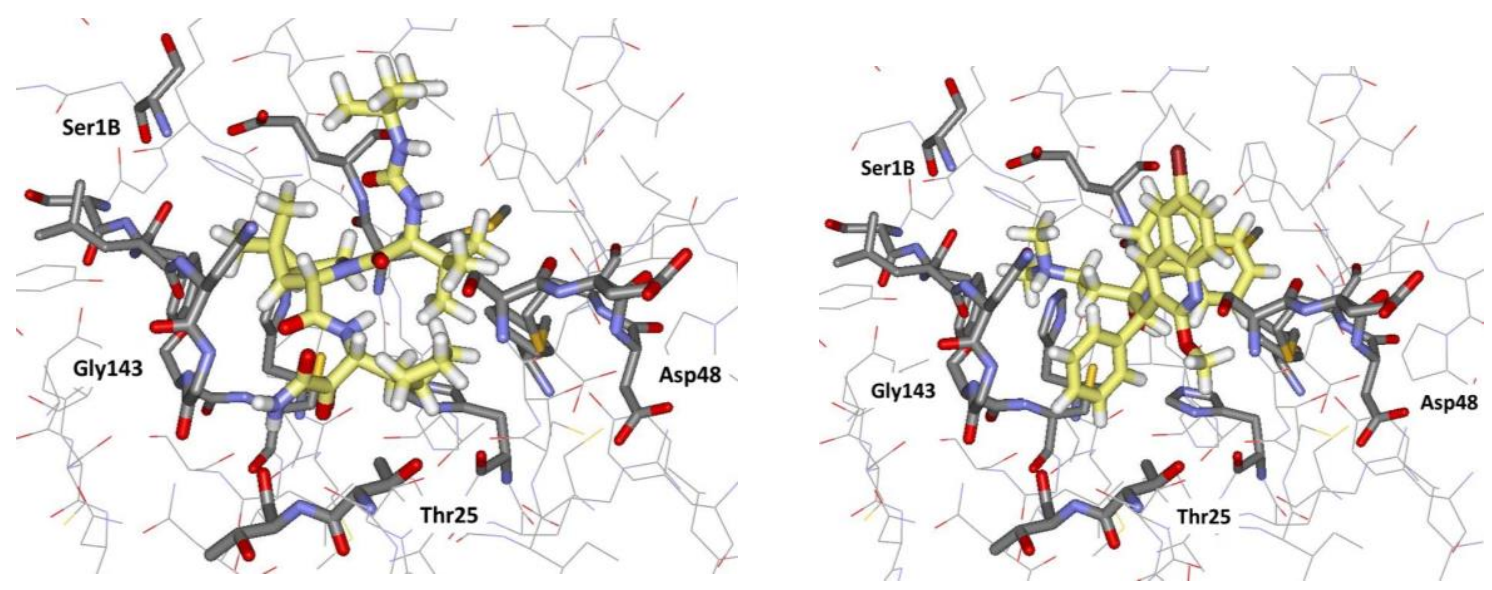

Figure 7. Renderings of Glide docking poses for (left) boceprevir, and (right) bedaquiline.

sit in P1, the sidechain with the cyclobutyl and terminal ketoamide groups is in P1', the t-butyl group is in P2, and there are hydrogen bonds with the NH of Gly143 and carbonyl oxygen of Thr26. For bedaquiline, the three pockets are occupied by the ammonium containing sidechain, the naphthyl group, and the phenyl group, 
respectively, while the quinoline fragment extends towards the solvent, and there are no clear protein-ligand hydrogen bonds. The activity of this compound does suggest that positively-charged groups may be acceptable in the P1 site.

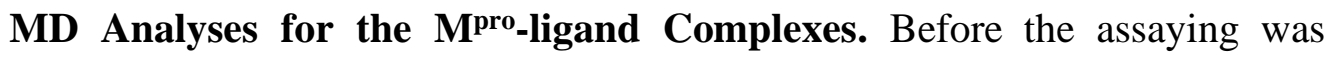
carried out, the 70-ns MD simulations were run for complexes of 14 of the promising compounds starting from the Glide poses. The idea was to obtain insight on which compounds gave more stable complexes and were, therefore expected to be more active inhibitors. In addition to visualization of the evolving structures, the all-atom RMSD of each ligand was computed over the course of the simulation time with and without least-square (LS) fitting of the ligand's atoms onto the initial orientation of the complex (Figure 8). The LS-fit RMSD monitors only the ligand's conformational changes, whereas the no-fit RMSD also reflects rotational and translational movements. The LS-fit RMSD converged relatively quickly to 2-3 A for all ligands, except for carindacillin, which converged to 4 A. However, as expected, no-fit RMSD values are larger than the LS-fit RMSD values for all ligands, demonstrating the contribution of rotational and translational movements. The no-fit RMSD value converged for bedaquiline, idarubicin, indinavir, and perampanel after about $10 \mathrm{~ns}$, while it converged for efonidpine after 60 ns. The no-fit RMSD values steadily fluctuated about an average value of $4 \AA$ for lapatinib and periciazine. In general, most ligands showed some displacement from their initial position, whereas they remained close to their initial conformation. Clear correlation of the results with the measured activities is not obvious, perhaps because $70 \mathrm{~ns}$ is too short a timeframe. For example, the RMSDs for bedaquiline and perampanel converge well, while they are more erratic for the more active boceprevir and efonidipine. More sophisticated MD procedures for gauging stability are known such as metadynamics, steered-MD, 

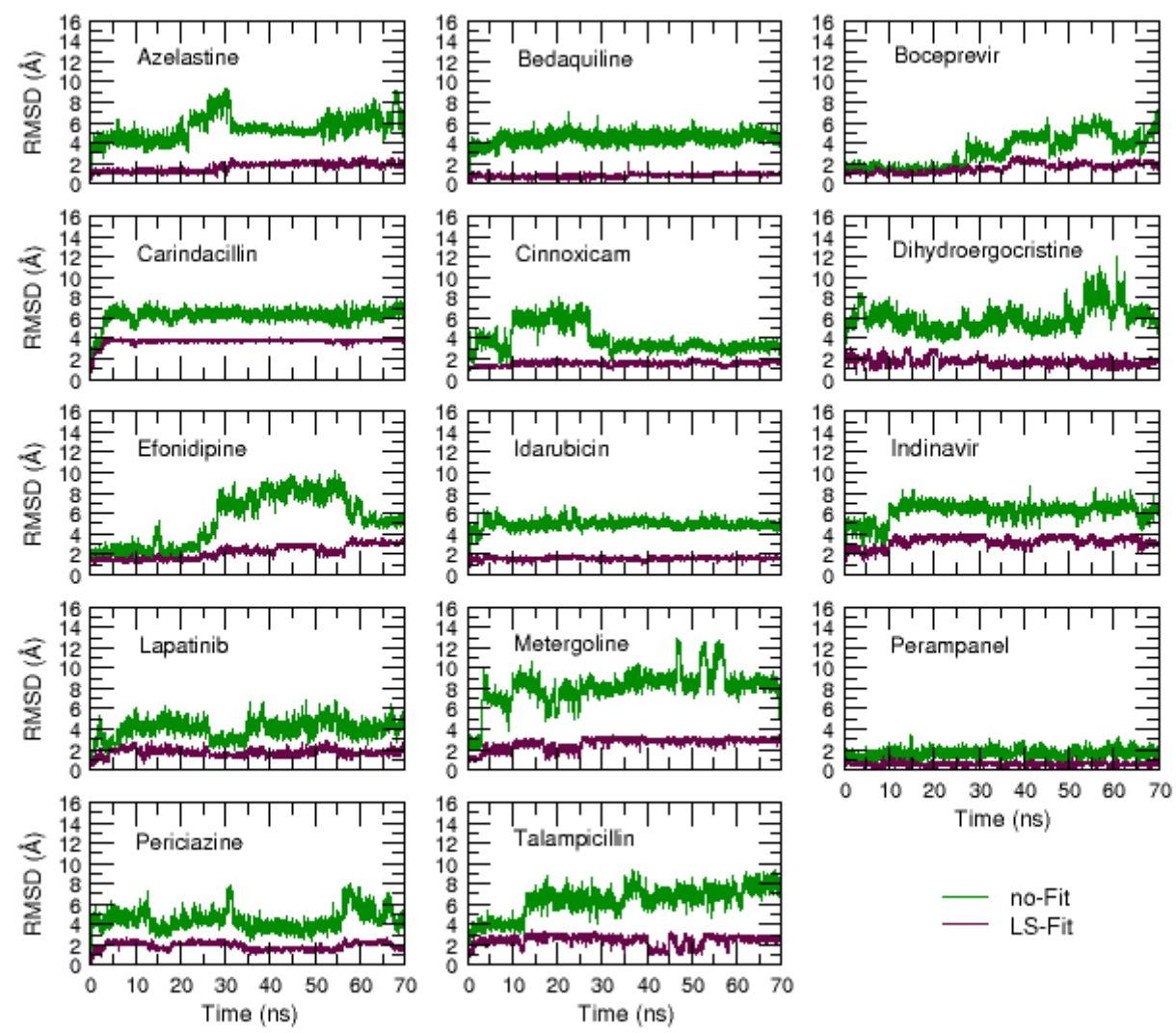

Figure 8. RMSD in $\AA$ of all ligand atoms with and without Least-Square fitting to the original complex structure during the course of 70-ns MD simulations.

and random-accelerated $\mathrm{MD},{ }^{46-49}$ which would be interesting to apply retrospectively to the present experimental results.

\section{CONCLUSIONS}

The present virtual screening study was highly successful in identifying 14 known drugs as showing inhibitory effect on the main protease of SARS-CoV-2. The consensus scoring approach using three docking programs and four protocols was effective in narrowing down ca. 2000 candidate drugs to 42 of high interest. The final 17 compounds that were selected for assay did reflect additional human visualization and analyses, though assaying of all 42 top compounds would not be burdensome. Five compounds were identified with $\mathrm{IC}_{50}$ values below $40 \mu \mathrm{M}$ with manidipine, 
boceprevir, lercanidipine, and bedaquiline having values of $4.8,5.4,16.2$, and 18.7 $\mu \mathrm{M}$. Further study of these compounds in the context of COVID-19 therapy is warranted, while all of the active compounds reported here may provide a foundation for lead optimization to deliver valuable chemotherapeutics to combat the pandemic.

\section{ASSOCIATED CONTENT}

\section{Supporting Information}

The Supporting Information is available free of charge on the ACS Publications website. An Excel file with the names and docking scores for the full drug library, a Figure with kinetic data for the assays of the five most active compounds, and a Figure comparing docking scores.

\section{AUTHOR INFORMATION}

\section{Corresponding Authors}

*E-mail: karen.anderson@yale.edu.

*E-mail: william.jorgensen@yale.edu

\section{ORCID}

Karen S. Anderson: 0000-0003-3433-0780

William L. Jorgensen: 0000-0002-3993-9520

\section{Notes}

The authors have no competing interests.

\section{ACKNOWLEDGMENTS}

Gratitude is expressed for support to the U. S. National Institutes of Health (GM32136) and to the Yale University School of Medicine for a CoReCT Pilot Grant. The $\mathrm{M}^{\text {pro }}$ plasmid was kindly provided by the Hilgenfeld lab. ${ }^{5}$ 


\section{REFERENCES}

(1) Wu, F.; Zhao, S.; Yu, B.; Chen, Y.-M.; Wang, W.; Song, Z.-G.; Hu, Y.; Tao, Z.W.; Tian, J.-H.; Pei, Y.-Y.; Yuan, M.-L.; Zhang, Y.-L.; Dai, F.-H.; Liu, Y.; Wang, Q.-M.; Zheng, J.-J.; Xu, L.; Holmes, E. C.; Zhang, Y.-Z. A New Coronavirus Associated with Human Respiratory Disease in China. Nature 2020, 579, 265-269.

(2) Jin, Z.; Du, X.; Xu, Y.; Deng, Y.; Liu, M.; Zhao, Y.; Zhang, B.; Li, X.; Zhang, L.; Peng, C.; Duan, Y.; Yu, J.; Wang, L.; Yang, K.; Liu, F.; Jiang, R.; Yang, X.; You, T.; Liu, X.; Yang, X.; Bai, F.; Liu, H.; Liu, X.; Guddat, L. W.; Xu, W.; Xiao, G.; Qin, C.; Shi, Z.; Jiang, H.; Rao, Z.; Yang, H. Structure of Mpro from SARS-CoV-2 and Discovery of Its Inhibitors. Nature 2020, 582, 289-293.

(3) Drosten, C.; Günther, S.; Preiser, W.; van der Werf, S.; Brodt, H.-R.; Becker, S.; Rabenau, H.; Panning, M.; Kolesnikova, L.; Fouchier, R. A. M.; Berger, A.; Burguière, A.-M.; Cinatl, J.; Eickmann, M.; Escriou, N.; Grywna, K.; Kramme, S.; Manuguerra, J.-C.; Müller, S.; Rickerts, V.; Stürmer, M.; Vieth, S.; Klenk, H.-D.; Osterhaus, A. D. M. E.; Schmitz, H.; Doerr, H. W. Identification of a Novel Coronavirus in Patients with Severe Acute Respiratory Syndrome. N. Engl. J. Med. 2003, 348, 1967-1976.

(4) Jin, Z.; Zhao, Y.; Sun, Y.; Zhang, B.; Wang, H.; Wu, Y.; Zhu, Y.; Zhu, C.; Hu, T.; Du, X.; Duan, Y.; Yu, J.; Yang, X.; Yang, X.; Yang, K.; Liu, X.; Guddat, L. W.; Xiao, G.; Zhang, L.; Yang, H.; Rao, Z. Structural Basis for the Inhibition of SARS-CoV-2 Main Protease by Antineoplastic Drug Carmofur. Nat. Struct. Mol. Biol. 2020, 27, 529-532.

(5) Zhang, L.; Lin, D.; Sun, X.; Curth, U.; Drosten, C.; Sauerhering, L.; Becker, S.; Rox, K.; Hilgenfeld, R. Crystal Structure of SARS-CoV-2 Main Protease Provides a Basis for Design of Improved $\alpha$-Ketoamide Inhibitors. Science 2020, $368,409-412$.

(6) Gimeno, A.; Mestres-Truyol, J.; Ojeda-Montes, M. J.; Macip, G.; SaldivarEspinoza, B.; Cereto-Massagué, A.; Pujadas, G.; Garcia-Vallvé, S. Prediction of Novel Inhibitors of the Main Protease (M-pro) of SARS-CoV-2 through Consensus Docking and Drug Reposition. Int. J. Mol. Sci. 2020, 21, 3793.

(7) Ma, C.; Sacco, M. D.; Hurst, B.; Townsend, J. A.; Hu, Y.; Szeto, T.; Zhang, X.; Tarbet, B.; Marty, M. T.; Chen, Y.; Wang, J. Boceprevir, GC-376, and Calpain Inhibitors II, XII Inhibit SARS-CoV-2 Viral Replication by Targeting the Viral Main Protease. Cell Res. 2020, 30, 678-692.

(8) Morse, J. S.; Lalonde, T.; Xu, S.; Liu, W. R. Learning from the Past: Possible Urgent Prevention and Treatment Options for Severe Acute Respiratory Infections Caused by 2019-nCoV. ChemBioChem 2020, 21, 730-738.

(9) Pushpakom, S.; Iorio, F.; Eyers, P. A.; Escott, K. J.; Hopper, S.; Wells, A.; Doig, A.; Guilliams, T.; Latimer, J.; McNamee, C.; Norris, A.; Sanseau, P.; Cavalla, D.; Pirmohamed, M. Drug Repurposing: Progress, Challenges and Recommendations. Nat. Rev. Drug Discov. 2019, 18, 41-58.

(10) Elfiky, A. A. Anti-HCV, Nucleotide Inhibitors, Repurposing against COVID-19. Life Sci. 2020, 248, 117477. 
(11) Choy, K.-T.; Wong, A. Y.-L.; Kaewpreedee, P.; Sia, S. F.; Chen, D.; Hui, K. P. Y.; Chu, D. K. W.; Chan, M. C. W.; Cheung, P. P.-H.; Huang, X.; Peiris, M.; Yen, H.-L. Remdesivir, Lopinavir, Emetine, and Homoharringtonine Inhibit SARS-CoV-2 Replication in Vitro. Antiviral Res. 2020, 178, 104786.

(12) Wang, Y.; Zhang, D.; Du, G.; Du, R.; Zhao, J.; Jin, Y.; Fu, S.; Gao, L.; Cheng, Z.; Lu, Q.; Hu, Y.; Luo, G.; Wang, K.; Lu, Y.; Li, H.; Wang, S.; Ruan, S.; Yang, C.; Mei, C.; Wang, Y.; Ding, D.; Wu, F.; Tang, X.; Ye, X.; Ye, Y.; Liu, B.; Yang, J.; Yin, W.; Wang, A.; Fan, G.; Zhou, F.; Liu, Z.; Gu, X.; Xu, J.; Shang, L.; Zhang, Y.; Cao, L.; Guo, T.; Wan, Y.; Qin, H.; Jiang, Y.; Jaki, T.; Hayden, F. G.; Horby, P. W.; Cao, B.; Wang, C. Remdesivir in Adults with Severe COVID19: A Randomised, Double-Blind, Placebo-Controlled, Multicentre Trial. The Lancet 2020, 395, 1569-1578.

(13) Goldman, J. D.; Lye, D. C. B.; Hui, D. S.; Marks, K. M.; Bruno, R.; Montejano, R.; Spinner, C. D.; Galli, M.; Ahn, M.-Y.; Nahass, R. G.; Chen, Y.-S.; SenGupta, D.; Hyland, R. H.; Osinusi, A. O.; Cao, H.; Blair, C.; Wei, X.; Gaggar, A.; Brainard, D. M.; Towner, W. J.; Muñoz, J.; Mullane, K. M.; Marty, F. M.; Tashima, K. T.; Diaz, G.; Subramanian, A. Remdesivir for 5 or 10 Days in Patients with Severe COVID-19. N. Engl. J. Med. 2020, NEJMoa2015301.

(14) Costanzo, M.; De Giglio, M. A. R.; Roviello, G. N. SARS CoV-2: Recent Reports on Antiviral Therapies Based on Lopinavir/Ritonavir, Darunavir/Umifenovir, Hydroxychloroquine, Remdesivir, Favipiravir and Other Drugs for the Treatment of the New Coronavirus. Curr. Med. Chem. 2020, 27, 4536-4541.

(15) Singh, A. K. Chloroquine and Hydroxychloroquine in the Treatment of COVID19 with or without Diabetes: A Systematic Search and a Narrative Review with a Special Reference to India and Other Developing Countries. Metab. Syndr. 2020, 14, 241-246.

(16) Yao, X.; Ye, F.; Zhang, M.; Cui, C.; Huang, B.; Niu, P.; Liu, X.; Zhao, L.; Dong, E.; Song, C.; Zhan, S.; Lu, R.; Li, H.; Tan, W.; Liu, D. In Vitro Antiviral Activity and Projection of Optimized Dosing Design of Hydroxychloroquine for the Treatment of Severe Acute Respiratory Syndrome Coronavirus 2 (SARSCoV-2). Clin. Infect. Dis. 2020, ciaa237.

(17) Geleris, J.; Sun, Y.; Platt, J.; Zucker, J.; Baldwin, M.; Hripcsak, G.; Labella, A.; Manson, D. K.; Kubin, C.; Barr, R. G.; Sobieszczyk, M. E.; Schluger, N. W. Observational Study of Hydroxychloroquine in Hospitalized Patients with COVID-19. N. Engl. J. Med. 2020, 382, 2411-2418.

(18) Fearon, D.; Powell, A.J.; Douangamath, A.; Owen, C.D.; Wild, C.; Krojer, T., Lukacik, P.; Strain-Damerell, C.M.; Walsh, M.A.; von Delft, F. PanDDA analysis of COVID-19 main protease against the DSI-poised Fragment Library. PDB ID: 5 R82.

(19) Word, J. M.; Lovell, S. C.; Richardson, J. S.; Richardson, D. C. Asparagine and Glutamine: Using Hydrogen Atom Contacts in the Choice of Side-Chain Amide Orientation. J. Mol. Biol. 1999, 4, 1735-1745.

(20) Olsson, M. H. M.; Søndergaard, C. R.; Rostkowski, M.; Jensen, J. H. PROPKA3: Consistent Treatment of Internal and Surface Residues in Empirical p $K_{\text {a }}$ Predictions. J. Chem. Theory Comput. 2011, 7, 525-537. 
(21) Gordon, J. C.; Myers, J. B.; Folta, T.; Shoja, V.; Heath, L. S.; Onufriev, A. H++: A Server for Estimating PKas and Adding Missing Hydrogens to Macromolecules. Nucleic Acids Res. 2005, 33, 368-371.

(22) Anandakrishnan, R.; Aguilar, B.; Onufriev, A. V. H++ 3.0: Automating PK Prediction and the Preparation of Biomolecular Structures for Atomistic Molecular Modeling and Simulations. Nucleic Acids Res. 2012, 40, 537-541.

(23) Pettersen, E. F.; Goddard, T. D.; Huang, C. C.; Couch, G. S.; Greenblatt, D. M.; Meng, E. C.; Ferrin, T. E. UCSF Chimera: A Visualization System for Exploratory Research and Analysis. J. Comput. Chem. 2004, 25, 1605-1612.

(24) Greenwood, J. R.; Calkins, D.; Sullivan, A. P.; Shelley, J. C. Towards the Comprehensive, Rapid, and Accurate Prediction of the Favorable Tautomeric States of Drug-like Molecules in Aqueous Solution. J. Comput. Aided Mol. Des. 2010, 24, 591-604.

(25) Shelley, J. C.; Cholleti, A.; Frye, L. L.; Greenwood, J. R.; Timlin, M. R.; Uchimaya, M. Epik: A Software Program for $\mathrm{p} K_{\mathrm{a}}$ Prediction and Protonation State Generation for Drug-like Molecules. J. Comput. Aided Mol. Des. 2007, 21, 681-691.

(26) Harder, E.; Damm, W.; Maple, J.; Wu, C.; Reboul, M.; Xiang, J. Y.; Wang, L.; Lupyan, D.; Dahlgren, M. K.; Knight, J. L.; Kaus, J. W.; Cerutti, D. S.; Krilov, G.; Jorgensen, W. L.; Abel, R.; Friesner, R. A. OPLS3: A Force Field Providing Broad Coverage of Drug-like Small Molecules and Proteins. J. Chem. Theory Comput. 2016, 12, 281-296.

(27) Friesner, R. A.; Banks, J. L.; Murphy, R. B.; Halgren, T. A.; Klicic, J. J.; Mainz, D. T.; Repasky, M. P.; Knoll, E. H.; Shelley, M.; Perry, J. K.; Shaw, D. E.; Francis, P.; Shenkin, P. S. Glide: A New Approach for Rapid, Accurate Docking and Scoring. 1. Method and Assessment of Docking Accuracy. J. Med. Chem. 2004, 47, 1739-1749.

(28) Halgren, T. A.; Murphy, R. B.; Friesner, R. A.; Beard, H. S.; Frye, L. L.; Pollard, W. T.; Banks, J. L. Glide: A New Approach for Rapid, Accurate Docking and Scoring. 2. Enrichment Factors in Database Screening. J. Med. Chem. 2004, 47, 1750-1759.

(29) Morris, G. M.; Huey, R.; Lindstrom, W.; Sanner, M. F.; Belew, R. K.; Goodsell, D. S.; Olson, A. J. AutoDock4 and AutoDockTools4: Automated Docking with Selective Receptor Flexibility. J. Comput. Chem. 2009, 30, 2785-2791.

(30) Trott, O.; Olson, A. J. AutoDock Vina: Improving the Speed and Accuracy of Docking with a New Scoring Function, Efficient Optimization, and Multithreading. J. Comput. Chem. 2009, 31, 455-460.

(31) Pronk, S.; Páll, S.; Schulz, R.; Larsson, P.; Bjelkmar, P.; Apostolov, R.; Shirts, M. R.; Smith, J. C.; Kasson, P. M.; van der Spoel, D.; Hess, B.; Lindahl, E. GROMACS 4.5: A High-Throughput and Highly Parallel Open Source Molecular Simulation Toolkit. Bioinformatics 2013, 29, 845-854.

(32) Robertson, M. J.; Tirado-Rives, J.; Jorgensen, W. L. Improved Peptide and Protein Torsional Energetics with the OPLS-AA Force Field. J. Chem. Theory Comput. 2015, 11, 3499-3509. 
(33) Jorgensen, W. L.; Chandrasekhar, J.; Madura, J. D.; Impey, R. W.; Klein, M. L. Comparison of Simple Potential Functions for Simulating Liquid Water. $J$. Chem. Phys. 1983, 79, 926-935.

(34) Jorgensen, W. L.; Tirado-Rives, J. Potential Energy Functions for Atomic-Level Simulations of Water and Organic and Biomolecular Systems. Proc. Natl. Acad. Sci. 2005, 102, 6665-6670.

(35) Jorgensen, W. L.; Tirado-Rives, J. Molecular Modeling of Organic and Biomolecular Systems Using BOSS and MCPRO. J. Comput. Chem. 2005, 26, 1689-1700.

(36) Dodda, L. S.; Cabeza de Vaca, I.; Tirado-Rives, J.; Jorgensen, W. L. LigParGen Web Server: An Automatic OPLS-AA Parameter Generator for Organic Ligands. Nucleic Acids Res. 2017, 45, 331-336.

(37) Essmann, U.; Perera, L.; Berkowitz, M. L.; Darden, T.; Lee, H.; Pedersen, L. G. A Smooth Particle Mesh Ewald Method. J. Chem. Phys. 1995, 103, 8577-8593.

(38) Hess, B.; Bekker, H.; Berendsen, H. J. C. LINCS: A Linear Constraint Solver for Molecular Simulations. J. Comput. Chem. 1997, 18, 1463-1472.

(39) Bussi, G.; Donadio, D.; Parrinello, M. Canonical Sampling through Velocity Rescaling. J. Chem. Phys. 2007, 126, 014101.

(40) Berendsen, H. J. C.; Postma, J. P. M.; van Gunsteren, W. F.; DiNola, A.; Haak, J. R. Molecular Dynamics with Coupling to an External Bath. J. Chem. Phys. 1984, 81, 3684-3690.

(41) Parrinello, M.; Rahman, A. Polymorphic Transitions in Single Crystals: A New Molecular Dynamics Method. J. Appl. Phys. 1981, 52, 7182-7190.

(42) Dai, W.; et al. Structure-based Design of Antiviral Drug Candidates Targeting the SARS-CoV-2 Main Protease. Science 2020, 368, 1331-1335.

(43) Pillaiyar, T.; Manickham, M.; Namasivayam, V.; Hayashi, Y.; Jung, S.-H. An Overview of Severe Acute Respiratory Syndrome - Coronavirus (SARS-CoV) 3CL Protease Inhibitors: Peptidomimetics and Small Molecule Chemotherapy. J. Med. Chem. 2016, 59, 6595-6628.

(44) Danta, C. C. Calcium Channel Blockers: A Possible Potential Therapeutic Strategy for the Treatment of Alzheimer's Dementia Patients with SARSCoV-2 Infection. ACS Chem. Neurosci. 2020, 11, 2145-2148.

(45) Vatansever, E. C.; Yang, K.; Kratch, K. C.; Drelich, A.; Cho, C. C.; Mellot, D.M.; $\mathrm{Xu}, \mathrm{S}$.; Tseng, C.K.; Liu, W. R. Targeting the SARS-CoV-2 Main Protease to Repurpose Drugs for COVID-19. bioRxiv [Preprint]. 2020 May 23:2020.05.23.112235. doi: 10.1101/2020.05.23.112235.

(46) Colizzi, F.; Perozzo, R.; Scapozza, L.; Recanatini, M.; Cavalli, A. SingleMolecule Pulling Simulations Can Discern Active from Inactive Inhibitors. J. Am. Chem. Soc. 2010, 132, 7361-7371.

(47) Cavalli, A.; Spitaleri, A.; Saladino, G.; Gervasio, F. L. Investigating DrugTarget Association and Dissociation Mechanisms Using Metadynamics-Based Algorithms. Acc. Chem. Res. 2015, 48, 277-285. 
(48) Kokh, D. B.; Amaral, M.; Bomke, J.; Grädler, U.; Musil, D.; Buchstaller, H.-P.; Dreyer, M. K.; Frech, M.; Lowinski, M.; Vallee, F.; Bianciotto, M.; Rak, A.; Wade, R. C. Estimation of Drug-Target Residence Times by $\tau$-Random Accelerated Molecular Dynamics Simulations. J. Chem. Theory Comput. 2018, 14, 3859-3869.

(49) Ruiz-Carmona, S.; Schmidtke, P.; Luque, F. J.; Baker, L.; Matassova, N.; Davis, B.; Roughley, S.; Murray, J.; Hubbard, R.; Barril, X. Dynamic Undocking and the Quasi-bound State as Tools for Drug Discovery. Nature Chem. 2017, 9, 201206. 